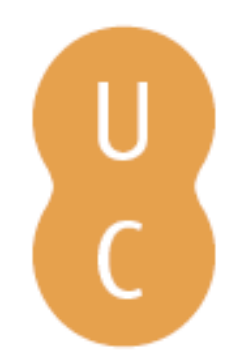

\title{
nommalina
}

\section{Decisão de continuar: a representação do colonialismo português em Moçambique nos inícios da guerra da libertação}

\author{
Autor(es): $\quad$ Schaefer, Ansgar \\ Publicado por: Imprensa da Universidade de Coimbra \\ URL \\ persistente: URI:http://hdl.handle.net/10316.2/43883 \\ DOI: $\quad$ DOI:https://doi.org/10.14195/978-989-26-1395-6_12 \\ Accessed : $\quad$ 26-Apr-2023 07:33:31
}

A navegação consulta e descarregamento dos títulos inseridos nas Bibliotecas Digitais UC Digitalis, UC Pombalina e UC Impactum, pressupõem a aceitação plena e sem reservas dos Termos e Condições de Uso destas Bibliotecas Digitais, disponíveis em https://digitalis.uc.pt/pt-pt/termos.

Conforme exposto nos referidos Termos e Condições de Uso, o descarregamento de títulos de acesso restrito requer uma licença válida de autorização devendo o utilizador aceder ao(s) documento(s) a partir de um endereço de IP da instituição detentora da supramencionada licença.

Ao utilizador é apenas permitido o descarregamento para uso pessoal, pelo que o emprego do(s) título(s) descarregado(s) para outro fim, designadamente comercial, carece de autorização do respetivo autor ou editor da obra.

Na medida em que todas as obras da UC Digitalis se encontram protegidas pelo Código do Direito de Autor e Direitos Conexos e demais legislação aplicável, toda a cópia, parcial ou total, deste documento, nos casos em que é legalmente admitida, deverá conter ou fazer-se acompanhar por este aviso.

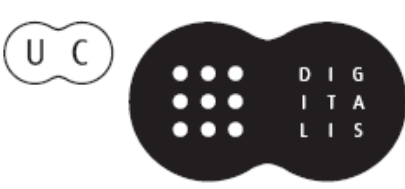



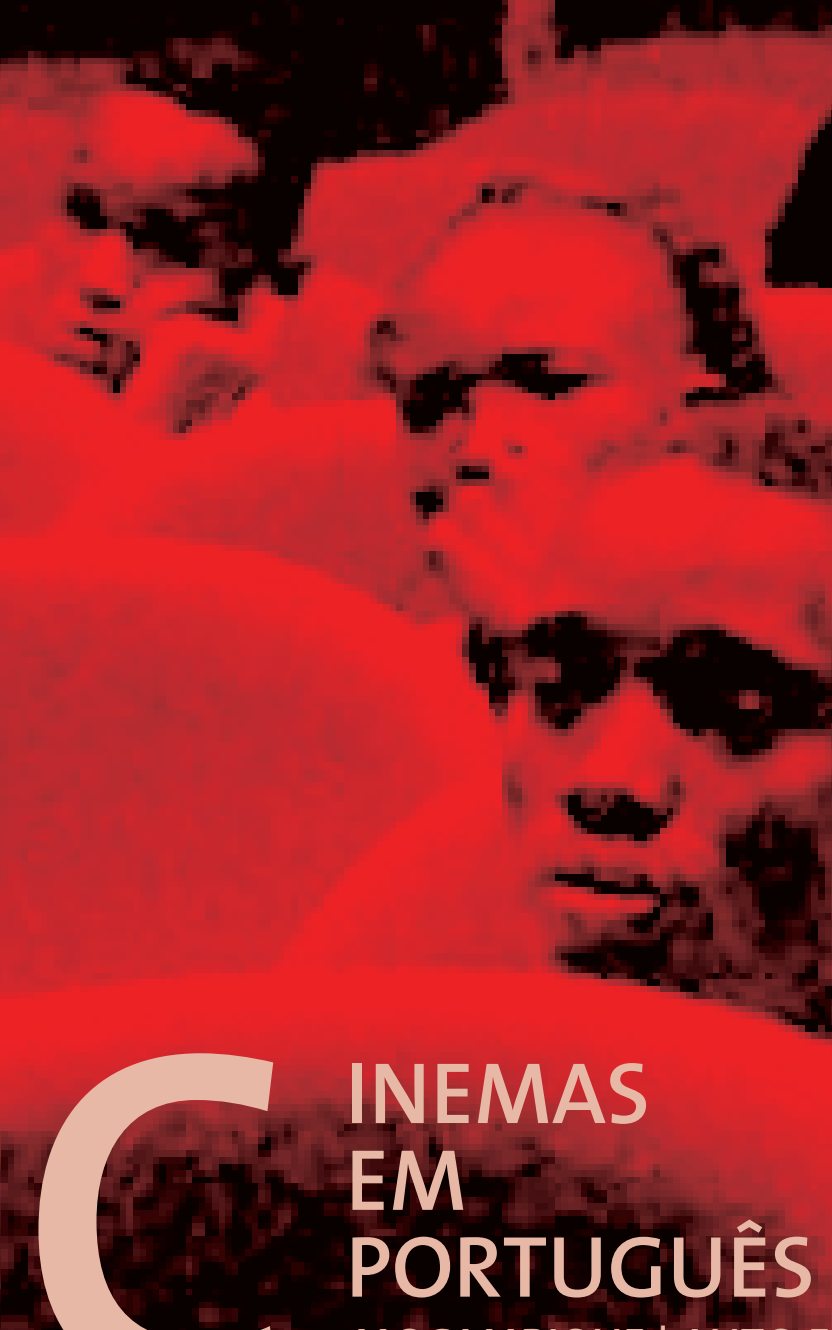

INEMAS

EM

PORTUGUÊS

MOÇAMBIQUE | AUTO E HETEROPERCEÇÕES

JORGE SEABRA

COORDENAÇÃO 


\title{
DECISÃO DE CONTINUAR. \\ A REPRESENTAÇÃO DO COLONIALISMO PORTUGUES \\ EM M O ÇA M B I Q U E \\ NOS INÍCIOS DA GUERRA DA LIBERTAÇÃO
}

\author{
Ansgar Schaefer \\ Universidade Nova de Lisboa \\ Investigador | Realizador | Produtor
}

Apesar de os primeiros trabalhos de historiadores que recorreram a documentos fílmicos como fontes para a sua investigação datarem já de há meio século, ainda hoje a atenção dada pela historiografia portuguesa ao cinema continua a ser escassa. Esta lacuna é tanto mais notória quando se relaciona a quantidade de estudos sobre o período do Estado Novo publicados ao longo das últimas décadas com o número de trabalhos que se debruçam sobre os documentos audiovisuais produzidos nessa época, uma situação todavia, à qual mais recentemente tem sido dada uma maior atenção ${ }^{1}$.

No presente texto pretendo analisar um trecho de 12 minutos do documentário Decisão de continuar, da autoria de José Eliseu, produzido pela então Radiotelevisão Portuguesa em 1965, cujo título não consta nem da obra de referência de José Matos Cruz (Matos-Cruz, 1989, p. 303) nem da Filmografia da Guerra Colonial ${ }^{2}$. A escolha des-

\footnotetext{
${ }^{1}$ A título de exemplo veja-se as mais recentes publicações de Maria do Carmo Piçarra.

${ }^{2}$ Filmografia / Videografia, Temas: Colonização - Guerra Colonial - 25 de Abril - Descolonização. Disponível em WWW: URL http://guerracolonial.home.sapo.pt.

DOI: https://doi.org/10.14195/978-989-26-1395-6_12
} 
te documentário prende-se com um episódio que ocorreu durante a investigação para a minha tese de doutoramento, a qual constitui uma reflexão sobre o relacionamento entre a historiografia tradicional e a historiofotia (Hayden White) - ou seja, a escrita da história através do cinema ou audiovisual - com base em alguns documentários feitos sobre os primeiros meses da guerra colonial em Angola (Schaefer, 2014). Um dos capítulos da tese consiste numa análise detalhada de um dos principais filmes de propaganda da altura chamado Angola: decisão de continuar ${ }^{3}$, um documentário encomendado à RTP pelo Secretariado Nacional de Informação (SNI). O filme, produzido com o objectivo de ser exibido sobretudo no estrangeiro, foi estreado na sala de cinema do Palácio Foz, em 8 de Agosto de 1961, na presença de um extenso rol de ministros e outras personalidades do regime, liderados pelo próprio Presidente Américo Thomaz ${ }^{4}$.

Durante os trabalhos de pesquisa, tive a oportunidade de entrevistar Vasco Hogan Teves, o autor e realizador deste documentário. Quando questionado sobre a história do título do filme, Hogan Teves mencionou um trabalho de um colega seu de então, José Eliseu, com um título muito semelhante: Decisão de continuar . Na época, Hogan Teves ressentiu-se muito do facto de lhe ter sido "roubado" o título do seu filme e em conversa privada abordou José Eliseu dizendo-lhe: "Pelo menos o título podias ter mudado", ao que este respondeu: "O título é do Salazar, não é teu" . Na verdade, o lema "decisão de continuar" consta do célebre discurso de Salazar, "O Ultramar Português e a ONU", proferido perante a Assembleia Nacional em 30 de Junho de 1961, pouco mais de três meses após os violentos ataques aos colonos

\footnotetext{
3 Secretariado Nacional de Informação - Angola: Decisão de Continuar, 1961.

4 "O Chefe do Estado no S.N.I." - O Século, 9/8/1961, p. 12.

${ }^{5}$ Decisão de continuar, RTP 1965, realizador: J. E. Eliseu, texto: Carlos Rodrigues, locução: Raul Feio, duração: 31:44. Uma cópia deste filme encontra-se no arquivo da RTP sob a cota: RTP LX, 031132 XD.

${ }^{6}$ Entrevista com Vasco Hogan Teves, 4 de Novembro de 2011.
} 
portugueses no norte de Angola, e no qual o Presidente do Conselho definiu a estratégia para a futura política colonial:

"Sejam quais forem as dificuldades que se nos deparem no nosso caminho e os sacrifícios que se nos imponham para vencê-las, não vejo outra atitude que não seja a decisão de continuar [destaque, A.S.] (Salazar, 1967, p. 157-158).”

Apesar da semelhança do título, há um elemento central que distingue estes dois documentários. Enquanto o filme de Vasco Hogan Teves foi concluído na primeira fase da guerra colonial em Angola, poucos dias antes da tomada de Nambuangongo, acontecimento exaustivamente festejado pela propaganda estado-novista, o documentário de José Eliseu foi realizado e emitido quatro anos mais tarde, mais concretamente a 15 de Março de 1965, para recordar os ataques que marcaram o início da guerra colonial em Angola. Nessa altura, porém, Portugal já não combatia em um mas em três teatros de guerra, tendo o número total de soldados portugueses duplicado nesses quatro anos de 49.422 para 97.181.

Partindo deste último documentário, a análise que me proponho fazer norteia-se por duas questões: face às semelhanças do título mas tendo em consideração o hiato de tempo, quais são as diferenças e continuidades que se podem identificar na mensagem propagandística de ambos? Três anos após o início da guerra colonial e seis meses após o começo do conflito em Moçambique, qual é a imagem deste território que Decisão de continuar pretende dar aos portugueses?

Olhemos, num primeiro momento, para a organização formal do filme. Este é constituído por quatro blocos: Após uma curta parte introdutória com uma duração de 3:25 minutos em que são recordados os momentos dramáticos após os ataques de Março de 1961 e a respectiva resposta militar portuguesa, segue-se um bloco onde é traçado um retrato da situação socio-económica de Angola após a intervenção militar (9:21 minutos). O terceiro bloco, o mais longo do filme (12:05 minutos) é exclusivamente dedicado à situação de Moçambique. 
O filme termina com um quarto bloco que funciona como uma espécie de epílogo (5:32 minutos) subdividido em três sequências que retratam a recepção do Presidente da República Américo Tomáz em Angola em 1963, as celebrações do Dia da Raça do 10 de Junho de 1964 e finalmente as despedidas e o embarque dos soldados para a África.

A presente análise limita-se exclusivamente às sequências deste filme que tematizam a presença portuguesa em Moçambique, ou seja ao bloco três. Este inicia-se com um plano da antena de uma emissora de rádio, filmado em contrapicado, uma perspectiva que realça a modernidade e a imponência desta estrutura metálica. Ao longo dos oito planos seguintes, a voz do narrador emudece e ouvimos exclusivamente o som diegético: as vozes de quatro jornalistas gravadas no local. A particularidade destes planos não é o facto de ouvirmos as suas vozes, mas o de os jornalistas falarem em quatro línguas diferentes: o primeiro em português, o segundo em inglês. A terceira e a quarta voz são de dois jovens jornalistas africanos que lêem os textos nas suas respectivas línguas maternas.

A sequência seguinte, que retrata o quotidiano de Lourenço Marques é a mais longa deste bloco. Começa com filmagens aéreas da cidade: à nossa frente desdobra-se uma cidade organizada, com ruas cuja fisionomia parece meticulosamente esculpida, com edifícios recentes onde poucos prédios se destacam num mar de moradias. Logo a seguir, a câmara desce para um parque onde duas crianças se deleitam a baloiçar. Segue-se um plano de dois rapazes virados de costas para a câmara, um dos quais é negro. Quando o segundo rapaz vira a sua cara para a câmara, reparamos que é branco. A sequência termina com mais dois planos que mostram crianças negras e brancas, sendo o último o mais paradigmático: um rapaz negro empurrando um carrinho com um bebé branco, ladeado por duas crianças brancas.

Sobre as imagens das crianças ouvimos o comentário do narrador:

"De ano para ano, a um ritmo crescente, vão surgindo mais e mais belos edifícios, largas avenidas, realizações que marcam o nosso es- 
forço, o nosso trabalho, a nossa única finalidade, em suma, de gente progressiva e civilizadora, apesar de tudo quanto apregoam alguns na sua ignorância e na sua má-fé" (Decisão de continuar, 1965, pls. 181-187).

Três aspectos destacam-se nestas palavras: a classificação do esforço e do trabalho dos portugueses como "a nossa única finalidade"; a caracterização dos portugueses como "gente progressiva e civilizadora"; e, finalmente o reconhecimento da existência de vozes críticas, um fenómeno explicado pelo narrador com a "ignorância" e "má-fé" dos seus autores.

Também os oito planos seguintes nos mostram o dia-a-dia nas avenidas de Lourenço Marques. Sobre imagens de cidadãos brancos e negros, estes últimos vestidos sempre à moda europeia, ouvimos a voz de Salazar que recorda os relatos de turistas estrangeiros, admirados pela beleza encontrada nas antigas colónias portuguesas. No final desta sequência, a câmara leva-nos a uma livraria. Enquanto olhamos para imagens de mesas e estantes repletas de livros, ouvimos a voz do narrador introduzir um elemento novo na sua argumentação:

"Vive-se aqui numa autêntica comunhão de princípios, no mais sincero e espontâneo entendimento, na mais concreta e real fraternidade de raças" (Decisão de continuar, 1965, pl. 195).

Segue-se uma pergunta retórica: "Tudo isto que acontece, teria acontecido se abandonado às leis do acaso?". Como resposta, o narrador cita as palavras do Papa Paulo VI:

"Sois filhos de uma nobre nação, que tanto se distinguiu pelos serviços prestados à Igreja e à humanidade, abrindo os caminhos do mar aos intrépidos missionários, portadores das verdades de Cristo, aos remotos países do Oriente e do Ocidente" (Decisão de continuar, 1965, pls. 197-198).

É de destacar que a referência ao passado cristianizador de Portugal é acompanhado por um corte para a imagem de um pintor que finaliza um quadro com a figura de um Cristo, curvado pelo peso da sua cruz 
invisível. Esta imagem marca a passagem para a sequência seguinte, dedicada à vida religiosa, que se inicia por uma imagem do exterior da Igreja da Polana, símbolo arquitectónico da vivacidade religiosa em Moçambique. No momento em que a imagem passa para o interior da igreja, a voz do narrador é substituída pelo som de um órgão. A câmara foca-se num dos vitrais que mostra a imagem da Nossa Senhora segurando Jesus ao seu colo. Ao longo de 15 segundos, sempre acompanhada pelo som do instrumento, a câmara desce lentamente pelo vitral tal como se estivesse à procura da fonte da música. Finalmente encontra-a: um jovem organista africano que toca devotamente. Após um corte para as mãos do organista, a câmara sobe pelo vitral seguinte que ostenta a imagem do Cristo Salvador, para regressar ao jovem organista africano filmado em plano aproximado.

Um plano muito aproximado de uma menina segurando um lápis marca o começo da sequência seguinte. Encontramo-nos numa escola, onde várias crianças, sentadas nas suas carteiras, aprendem a escrever. Vejamos como o narrador acompanha esta cena:

"Misturam-se as raças nas mais diversas actividades. No campo, nas oficinas e nos bancos das escolas. A origem, a cor, os idiomas não importam. Todos se agrupam indiscriminadamente para um só objectivo, o engrandecimento de Moçambique, terra portuguesa" (Decisão de continuar, 1965, pls. 214-216).

Uma particularidade, no entanto, caracteriza todas as imagens desta sequência. Apesar do destaque dado pelo narrador à "mistura das raças", alegadamente uma das principais características de Moçambique, não só as crianças e o seu professor têm traços orientais como também o manual escolar é escrito em caracteres chineses. Como explicar esta manifesta contradição? Estamos, nesta cena, perante o mecanismo típico de filmes de propaganda: o uso persuasivo de um narrador em voz off. Devido à invisibilidade e ao anonimato do narrador, o espectador confere-lhe a aura de objectividade e imparcialidade de um espectador absoluto, alguém que testemunha as coisas tal como 
são (Niney, 2009, p. 112-113). Ora, devido a esta aura de objectividade do narrador, o espectador vive na ilusão de encontrar à sua frente a prova visual do discurso que está a ouvir. Roland Barthes designa a interacção entre uma imagem fotográfica e um texto como "naturalização do cultural". As naturezas denotacionais e conotacionais de fotografia e texto produzem o efeito de que: "Quanto mais perto o texto estiver em relação à imagem, tanto menos parece conotá-la; [o texto é] compreendido tal como se estivesse dentro da mensagem iconográfica, a mensagem verbal parece partilhar a sua objectividade, a conotação do discurso é tornada "inocente" pela denotação da imagem fotográfica" (Barthes,1977, p. 26). Neste caso concreto, perante a afirmação do narrador da existência de uma sociedade impregnada pela mistura das raças, o espectador deixa de ler as imagens que se encontram à sua frente e aceita-as, tal como pretendido pelo cineasta, como prova visual do discurso verbal.

Após estas imagens passamos para as três sequências finais deste bloco destinadas a documentar o progresso da economia moçambicana. Após um plano de uma locomotiva em andamento, filmada em picado, olhamos para vagões intermináveis que transportam carvão. Acompanhada pela voz de Salazar, que cita dados estatísticos sobre o aumento do investimento português nas infra-estruturas portuárias, a câmara passa a mostrar-nos barcos atracados no porto. No momento em que o discurso de Salazar aborda os investimentos feitos na rede ferroviária, o espectador vê imagens de um comboio de mercadoria e um imensa rede ferroviária, filmadas a partir de um comboio em andamento. O próprio movimento do comboio cria a transição para a penúltima sequência. Viajamos ao som de um comboio pelo meio de uma extensa plantação de palmeiras. Sobre a imagem de um rapaz africano que sobe uma destas árvores, o narrador afirma:

"Por outro lado, as facilidades de comunicações fomentam o aproveitamento das riquezas naturais. Aqui, na imensa Zambézia, hoje surpreendente de beleza, perderam a vida muitos dos ousados 
portugueses, que inscreveram palmo a palmo na terra inexplorada o nome de Portugal. [...]

A pecuária e a agricultura, dois factores preponderantes nesta imensidão da Zambézia, talvez nos façam lembrar aqueles estádios inferiores de pobreza em que viviam há séculos estas gentes.

Estes estádios progressivamente foram vencidos pela ordem sem desarticular a sua forma peculiar de vida" (Decisão de continuar, pls. 246 - 257).

Encontramos nesta passagem um novo tópico do discurso propagandístico colonial: o do sacrifício dos portugueses, que não só transformou a "terra inexplorada" em local de fertilidade e beleza como, ao mesmo tempo, permitiu que a população africana pudesse sair "(d)aqueles estádios inferiores de pobreza em que viviam há séculos". O bloco termina com 24 planos, maioritariamente curtos, retirados do mundo de trabalho.

Vejamo-los com mais detalhe: logo no primeiro plano, a câmara apresenta-nos a cara de um empregado africano. O enquadramento, uma filmagem por cima dos ombros desta personagem, permite-nos observá-la a terminar, concentradamente, um desenho técnico. Também a imagem seguinte se centra num jovem africano que, envergando uma bata branca, trabalha num laboratório. No plano de fundo da imagem, um jovem branco, aparentemente, exerce a mesma função. Segue-se um corte para uma sala de aulas. Filmada em picado, a imagem assume a perspectiva do professor que olha para a sua turma, uma perspectiva que nos permite observar as caras dos alunos. Contamos um total de 22 rapazes, cinco dos quais africanos. Do ambiente escolar passamos para uma fábrica têxtil onde uma dezena de mulheres trabalha nas máquinas de costura. Novamente no centro da imagem, uma operária africana, cuja figura é isolada pela câmara no plano seguinte. Os próximos seis planos mostram-nos sempre operários portugueses juntamente com moçambicanos. Se nos primeiros quatro planos, a participação dos trabalhadores moçambicanos é de natureza 
passiva, encontrando-se estes na margem da imagem a observar o trabalho dos colegas brancos, nos últimos dois planos o seu papel é claramente activo. A imagem mais paradigmática é certamente a de duas funcionárias administrativas, uma branca e a outra negra que exercem a mesma tarefa: inserir dados em computadores à base de cartões perfurados.

Nesta curta sucessão de imagens testemunhamos a elevação do estatuto do africano dentro do mundo de trabalho. De um mero sujeito passivo colocado à margem da imagem, este evolui para um elemento plenamente integrado no processo do trabalho. A mensagem da alegada igualdade entre brancos e negros no mundo profissional domina também os restantes planos desta sequência. No primeiro, um dos poucos planos longos deste grupo de imagens, olhamos para o rosto de um trabalhador africano, sentado na mesa de uma cantina, a comer um prato de sopa. A câmara inicia um movimento panorâmico horizontal que termina num operário branco, que, aparentemente, come a mesma comida que o seu colega. Segue-se um corte para a imagem de um consultório onde um médico branco examina um paciente negro de tronco nu, assistido por um enfermeiro africano. Imediatamente a seguir, a câmara mostra-nos o enfermeiro a tirar sangue a um paciente. O final da sequência é constituído por seis planos filmados numa oficina de grandes dimensões, onde todas as máquinas são operadas exclusivamente por trabalhadores africanos. Todas estas imagens são acompanhadas por um discurso dominado pela voz de Salazar.

“(...) Numa sociedade de homens o que acima de tudo importa é o tipo das relações humanas. A maneira de ser portuguesa, os princípios morais que presidiram aos descobrimentos e à colonização, fizeram que em todo o território nacional seja desconhecida qualquer forma de discriminação e que se hajam constituído sociedades plurirraciais, impregnadas do espírito de convivência amigável e só por isso pacífica" (Decisão de continuar, pls. 265 - 276). 
Reencontramos nestas palavras de Salazar o típico discurso luso-tropicalista com as suas referências à convivência amigável e à inexistência da discriminação racial, elementos discursivos centrais neste documentário. Salazar termina a sua celebração da sociedade multirracial com uma referência à "integração política" que "não derivaria de uma assimilação completa, mas sobretudo da confraternização estabelecida sem distinção de credos ou de cores" (Decisão de continuar, pls. 276 - 281).

Também estas frases de Salazar têm origem no seu célebre discurso "O Ultramar Português e a ONU". Sobre as últimas imagens dedicadas à presença portuguesa em Moçambique, o narrador retoma a palavra:

"É neste ambiente de trabalho, nesta comunhão de princípios, nesta identidade criada através dos séculos que a África continua a precisar de nós.

E a decisão de continuar, o dever de ficarmos está implícito no nosso destino histórico, na nossa missão de servir e de fazer cristandade. Aqui, em Moçambique como em Angola, é de facto Portugal " (Decisão de continuar, pls. 282 - 287).

Olhando para a estrutura formal do filme, constatamos que Decisão de continuar é um filme de compilação, ou seja, utiliza materiais filmados para outros objectivos do que os do filme em análise ${ }^{7}$. No filme em questão, a estratégia discursiva verbal baseia-se em dois vectores argumentativos: trechos de discursos de Salazar gravados ao vivo, combinados com os comentários de um narrador omnisciente e invisível. Enquanto cabe ao antigo lente conimbricence a função do docere, ou seja a argumentação de cariz científica, baseada numa panóplia de dados estatísticos, cabe ao narrador interpretar as imagens do filme.

7 Susana de Sousa Dias destaca como características de filmes de compilação os seguintes elementos 1) planos, não necessariamente relacionados e retirados de diversos filmes; 2) uma temática (ou um conceito) que motiva a selecção dos planos e a sua justaposição; 3) uma voz over ou excertos de textos que conduzem o espectador, condicionando-o a uma interpretação das imagens e sons de acordo com a intenção do autor"; cf.: Dias, 2005, p. 42-43. 
Desenrolam-se à nossa frente imagens de um Moçambique moderno, próspero e ordenado, muito ao estilo das capitais europeias, um lugar onde convivem em plena harmonia as mais diversas culturas. Apesar de uma clara predominância de imagens que juntam africanos e portugueses, a convivência entre as raças, constantemente afirmada pelo discurso verbal, nunca se traduz - salvo nas imagens das crianças -, numa verdadeira interacção entre brancos e negros.

O discurso visual apresenta-nos, todavia, um processo de emancipação do africano. O "Outro" africano, nunca nos é apresentado numa posição de subalternidade tal como na qualidade de empregado ou criado de mesa, mas como aluno ou aprendiz que futuramente irá exercer as mesmas funções e assumir as mesmas responsabilidades como os seus colegas brancos.

É de frisar, porém, que todas as tarefas por estes realizadas não só reflectem um elevado investimento por parte do instruendo, como também do instrutor, ou seja, o regime colonial através dos seus agentes de ensino, segundo a linha argumentativa do sistema colonial. Que a realidade de Moçambique não correspondia em nada à imagem apresentada no filme mostra-nos Joaquim Furtado no quinto episódio da série A guerra, em que várias testemunhas recordam as inúmeras discriminações raciais às quais eram sujeitas na altura em questão. Se as mais evidentes foram as restrições de acesso a cinemas e restaurantes ( $A$ guerra, 2007, pl. 213) ou a existência de apenas cinco lugares sentados disponíveis para africanos nos autocarros (A guerra, 2007, pl. 214), muito mais graves eram os castigos corporais aplicados aos trabalhadores africanos, bem como a sua discriminação legal.

O bloco dedicado a Moçambique do filme de José Eliseu, todavia, não só pretende justificar a existência do colonialismo através das suas alegadas características particulares e benesses para a população africana, mas também através da história. Ao afirmar, tal como se se tratasse de um dado adquirido, que a terra encontrada era "terra inexplorada" onde os povos viviam num estado de miséria, a voz do 
filme (no sentido de Bill Nichols) (Nicols, 2001, p. 43) reclama o direito dos portugueses "de estar" em África devido ao "suor" e ao "sangue" derramados nestas terras no desempenho da sua missão histórica "de servir e de fazer cristandade" (Decisão de continuar, pl. 286). Com esta mensagem, o documentário de José Eliseu combina dois paradigmas da propaganda colonial portuguesa: a missão evangelizadora e o luso-tropicalismo.

Decisão de continuar reproduz o tradicional discurso colonial estado-novista, de cariz imperial, caracterizado pela sua "vocação histórico-providencial de colonizar e evangelizar" (Rosas, 2012, p. 324) que encontrava a sua expressão máxima no art. $^{\circ} 2^{\circ}$ do Acto Colonial de Julho de 1930. Este afirmava que era "da essência orgânica da nação portuguesa desempenhar a função histórica de possuir e colonizar domínios ultramarinos e de civilizar as populações indígenas que neles se compreendam [...]»8. Este discurso apenas foi abandonado em pleno período das descolonizações do pós-guerra. Ao rebaptizar as "colónias" em "províncias ultramarinas", administradas não pelo Ministério das Colónias mas pelo Ministério do Ultramar, o regime procurava refutar as acusações de Portugal ser um estado colonial, argumentando não possuir colónias mas províncias ultramarinas, sendo, por este motivo, qualquer ataque contra a sua política nestes territórios uma interferência em assuntos internos. A argumentação estado-novista encontrou um aliado importante na figura do reputado sociólogo e historiador brasileiro Gilberto Freyre (1900-1987) cuja teoria do luso-tropicalismo se pode resumir num pensamento principal: o da singularidade do colonialismo português. Freyre defendia que o colonialismo português era diferente do dos restantes povos europeus, porque enquanto estes se conservavam "intransigentemente europeus nas áreas tropicais” (Freyre, 1961, p. 74), os portugueses estabeleceriam

8 Citado por Sousa, 2008, p. 177. 
relações especiais, dando assim origem a "uma verdadeira "civilização luso-tropical»" (Alexandre, 1996, p. 434).

Se a tentativa de justificar a presença portuguesa em África através da alegada particularidade do colonialismo português é um aspecto que já se encontrava no documentário Angola: Decisão de Continuar de 1961, o filme de José Eliseu de 1965 vai ainda mais longe na sua argumentação. Recordemos as duas imagens de Cristo que surgem no filme, uma pintura de um Cristo curvado sob o peso da cruz, e o retrato do Cristo Salvador, representado nos vitrais da Igreja da Polana. A cruz que Cristo carrega para salvar o mundo através do seu autosacrifício traduz-se no filme de José Eliseu no dever dos portugueses de permanecer em África, um dever que, como afirma o narrador, "está implícito no nosso destino histórico, na nossa missão de servir e de fazer cristandade" (Decisão de continuar, pl. 286). Encontramos a mesma ideia nas palavras do narrador que acompanham as imagens dos soldados a subirem para o barco que os leva a África:

"É neles que nós, os que ficamos, confiámos a defesa da paz e da civilização" (Decisão de continuar, pl. 352).

Imanente a esta ideia da salvação da civilização cristã está a dicotomia clássica do discurso propagandístico, a da divisão do mundo num lado nobre e num lado selvagem, enquadrando, assim, a presença portuguesa em África na luta eterna entre as forças do bem e do mal, motivo típico dos filmes de propaganda?

No seu filme Decisão de continuar, José Eliseu não limita o sacrifício aos portugueses residentes em África como era típico para os filmes dos anos anteriores, mas alarga-o a todos os portugueses. Presenciamos esta mudança de paradigma não só na parte inicial do filme, nomeadamente nos planos dos soldados portugueses feridos em combate, mas também na parte final, num pormenor que marca

9 Cf. a análise dos filmes da propaganda nazi feita por Siegried Kracauer. Kracauer, 1971, p. 291. 
uma ruptura total com a propaganda militar de 1961. Se nessa altura, como nos explicou Vasco Hogan Teves, nas reportagens de guerra era proibido "mostrar na partida lenços a acenar e mulheres a chorar", quatro anos mais tarde, esta situação tinha-se alterado profundamente. Na verdade, o novo tópos das "lágrimas das mães" é já parte integrante da prática discursiva do próprio presidente do Conselho, António de Oliveira Salazar. No seu discurso "Erros e Fracassos da Era Política", parcialmente citado no filme, podemos ler o seguinte:

"Vamos a quatro anos de lutas e ganhou-se alguma coisa com o dinheiro do povo, o sangue dos soldados, as lágrimas das mães? Pois atrevo-me a responder que sim. No plano internacional, (...) acabaram muitos dos homens mais responsáveis por vir a reconhecer que Portugal se bate afinal não só para firmar um direito seu mas para defender princípios e interesses comuns a todo o Ocidente" (Salazar, 1967, pp. 367-368).

Apesar desta expressa referência ao sangue dos soldados e às lágrimas das mães, o documentário apresenta-nos a "África portuguesa" como sucesso da missão colonizadora e como espaço de harmonia e paz celestial, deliberadamente ignorando a nova realidade caracterizada por actividades bélicas em três teatros de guerra separados por milhares de quilómetros. Iniciado pelas imagens da chegada ao aeroporto de Luanda dos sobreviventes dos ataques de Março de 1961, o filme pretende mostrar o sucesso da "Decisão de Continuar" afirmada por Salazar. No entanto, toda a lógica narrativa comporta um paradoxo: se a guerra foi, como o filme alega, não mais do que um curto episódio já pertencente ao passado e se o ambiente reinante é de paz e harmonia, por que razão continuam as celebrações militares do dia 10 de Junho com as condecorações dos militares regressados e o envio de novos contingentes para a África?

No mesmo discurso «Erros e Fracassos da Era Política» Salazar afirma: "O homem que fica, vivo ou morto, ocupa de facto o território; o que abala, deserta e abandona-o" (Salazar, 1967, p. 367). O documentário 
de José Eliseu, exibido em 15 de Março de 1965 para recordar os ataques de 1961, visava inculcar na consciência do público televisivo de Portugal continental a necessidade da presença portuguesa em África a qualquer custo. No entanto, o apelo ao "ficar", apelidado pela propaganda do regime como dever de cada português por força da sua missão civilizacional e colonizadora, teria, na verdade, dois objectivos: por um lado conservar o "Império Colonial", construção mítica na qual se sustentava toda a ideologia do regime e, por outro - e este aspecto é decorrente do primeiro -, garantir a sobrevivência do regime e dos seus governantes. Como se viu no 25 de Abril, a queda de um implicou a derrocada do outro.

\section{Referências}

\section{Fílmicas}

A guerra. Episódio 5, Portugal, RTP, 2007

Angola - Decisão de continuar, Portugal, SNI, 1961

Decisão de continuar, Portugal, RTP, 1965

\section{Bibliográficas}

Alexandre, Valentim - "Ideologia Colonial", in Dicionario de História do Estado Novo, Vol. 1, A-L, direcção de Rosas, Fernado; Brandão de Brito, J. M., Venda Nova: Bertrand Editora, 1996, pp. $432-434$.

Barthes, Roland - "The Photographic Message", Image, Music, Text." Essays selected and translated by Stephen Heath, New York: Hill and Wang, 1977.

Entrevista com Vasco Hogan Teves, 4 de Novembro de 2011.

Filmografia / Videografia, Temas: Colonização - Guerra Colonial - 25 de Abril - Descolonização. Disponível em WWW: <URL http://guerracolonial.home.sapo.pt.

Freyre, Gilberto - "Outros aspectos da civilização que possa ser considerada luso-tropical." in Gilberto Freyre, O luso e o trópico, Comissão Executiva das Comemorações do Quinto Centenário da Morte do Infante D. Henrique, Lisboa 1961, pp. 49 - 61.

Herlihy David, - "Am I a Camera? Other Reflections on Films and History", The American Historical Review, Vol. 93, N. ${ }^{\circ}$ 5, p. 1186-1192.

Kracauer, Siegfried - "Propaganda and the Nazi War Film. Supplement", From Caligari to Hitler. A psycological history of the German Film, $4^{\mathrm{a}}$ ed., Princeton, Princeton University Press, 1971.

Matos-Cruz, José - Prontuário do Cinema Português, Lisboa: Cinemateca Portuguesa, 1989. 
Nicols, Bill - Introduction to Documentary, Bloomington and Indianapolis: Indiana University Press, 2001.

Niney, François - Le documentaire et ses faux-semblants, $1^{\text {a }}$ ed. Paris: Klincksiek, 2009.

“O Chefe do Estado no S.N.I.”, O Século, 9/8/1961, p. 12.

Rosas, Fernando - Salazar e o Poder. A arte de saber durar, Lisboa: Tinta da China edições, 2012.

Rosenstone, Robert A. - "History in Images/History in Words: Reflections on the Possibility of Really Putting History onto Film”, in The American Historical Review, Vol. 93, No. 5, pp. 1200-1209.

Salazar, António Oliveira de - "Erros e Fracassos da Era Política", in Salazar, António Oliveira de - Discursos e Notas Politicas, VI - 1959-1966. Coimbra, Coimbra Editora, 1967, pp. 351 - 378.

Salazar, António Oliveira de - "O Ultramar Português e a ONU. Discurso proferido na sessão extraordinária da Assembleia Nacional, em 30 de Junho de 1961”. In Salazar, António Oliveira de - Discursos e Notas Políticas VI - 1959-1966. Coimbra, Coimbra Editora, 1967.

www.guerracolonial.org/specific/guerra_colonial/uploaded/graficos/estatiscas/efectivos.swf.

Schaefer, Ansgar - Representar a História: Potencial e Limites do Documentário Histórico na Divulgação do Passado. Tese de Doutoramento em História, especialidade História Contemporânea, Lisboa: Universidade Nova de Lisboa, 2014.

Sousa Dias de Macedo, Susana de - Do Inventário à Invenção. Cinema, Arquivo, Memória, Tese de Mestrado em Estética e Filosofia da Arte, [Texto policopiado], Lisboa: Faculdade de Letras, Universidade de Lisboa, 2005.

Sousa, Pedro Miguel - O colonialismo de Salazar. Texto integral do Acto Colonial, Lisboa: Via Ocidentalis Editora, 2008. 